Rev. Hist., N²8, vol. 1, Enero-Junio 2021: 289-318

ISSN 0717-8832

https://doi.org/10.29393/RH28-11MCKC20011

\title{
Del mutualismo al Centro Femenino Anticlerical Belén de Sárraga: trayectoria de la participación sociopolítica de mujeres en Iquique (1890-1918)
}

\author{
From mutualism to the Belén de Sárraga Anti-clerical Women's Centre: trajectory of \\ the women's socio-political participation in Iquique (1890-1918)
}

Karelia Cerda Castro*
Damián Lo Chávez

\section{RESUMEN}

El objetivo de este artículo, es analizar la participación sociopolítica de mujeres en el movimiento obrero, entre fines del siglo XIX e inicios del XX, a partir de la experiencia del Centro Femenino Anticlerical Belén de Sárraga, desde una perspectiva histórica. Las fuentes utilizadas corresponden principalmente a prensa obrera de la época, archivos de la Alcaldía Municipal y otros documentos de la administración pública. Los resultados obtenidos, consisten en un balance de las transformaciones operadas en las formas de organización de las mujeres de sectores populares, en proceso de politización.

Palabras clave: Mujeres, participación sociopolítica, mutualismo, librepensamiento, anticlericalismo, Belén de Sárraga.

\section{ABSTRACT}

The objective of this article is to analyze the socio-political participation of women in the labor movement, between the end of the 19th century and the beginning of the 20th, based on the experience of the Belén de Sárraga Anti-clerical Women's Center, from an historical perspective. The sources used correspond mainly to the working press of the period, archives of the Municipality and other documents of the public administration. The results obtained are a balance of the transformations carried out in the forms of grassroots women's organization, in the process of politicization.

Keywords: Women, socio-political participation, mutualism, freethought, anti-clericalism, Belén de Sárraga.

Recibido: febrero 2021

Aceptado: mayo 2021

\footnotetext{
* Licenciada en Historia, Universidad de Chile. Magíster en Historia, Universidad de Tarapacá. Departamento de Ciencias Históricas y Geográficas, Universidad de Tarapacá, Chile. ORCID: https://orcid.org/0000-0002-98504156.Correo electrónico: karelia.cerda@gmail.com.

** Licenciado en Historia, Universidad de Chile. Magíster en Historia, Universidad de Tarapacá. Doctorando en Historia, Universidad de Tarapacá, Chile. ORCID: https://orcid.org/0000-0002-1744-2513. Correo electrónico: damianernesto.lo@gmail.com.
} 


\section{Introducción}

La historiografía chilena se ha ocupado extensamente del surgimiento de la clase obrera en la región salitrera en el contexto en que situamos esta investigación, principalmente desde la historia social, analizando las diversas formas de organización de los trabajadores surgidas en el contexto de transición capitalista en Chile. Diversos autores se han referido a la existencia de organizaciones de mujeres, sin embargo, no han profundizado en su estudio, apuntando a ejemplificar la amplitud y diversidad de la asociatividad popular y la transversalidad de las demandas de la clase trabajadora ${ }^{1}$.

Proponemos analizar esta temática a partir del enfoque de género como principal perspectiva teórica. La categoría de género, siguiendo a Joan W. Scott, es comprendida como "un elemento constitutivo de las relaciones sociales basadas en las diferencias que distinguen los sexos y el género es una forma primaria de relaciones significantes de poder" ${ }^{2}$. En ese sentido, se establece que el género es una construcción sociocultural que articula roles y atribuciones a los sujetos en base a sus diferencias anatomofisiológicas, por tanto su incorporación a la investigación histórica permite abordar distintos aspectos del quehacer humano en donde se expresan dichas diferencias, en el caso particular de esta investigación resulta ser un elemento clave para comprender y problematizar la participación sociopolítica de las mujeres en el movimiento obrero.

Por otra parte, creemos relevante reemplazar la visión parcial que ha predominado en la historiografía nacional al referirse al sujeto mujer, la cual enfoca su atención primordialmente en mujeres célebres o vinculadas con un hombre destacado, generando una interpretación de su presencia en la historia como casualidad o accidentalidad, a la vez que se resta historicidad al significado de sus acciones. La historia social ha permitido visibilizar a las mujeres en tanto que sujetos subalternos, sin embargo concordamos con Isabel Núñez en que "La mujer del bajo pueblo es el objeto de estudio por excelencia de esta línea historiográfica, que inscribe a las mujeres como sujetos complementarios de los procesos históricos, construyendo una dialéctica de clase escasamente reflexiva, invisibilizando las relaciones de poder que se generan en los procesos" 3 . Es por tanto necesario generar mayor problematización tanto de su presencia como de las implicancias del género en el desarrollo de los procesos sociales.

Esta investigación busca analizar a las mujeres en una perspectiva colectiva que permita otorgar sentido y continuidad a su protagonismo en los procesos históricos del norte salitrero, a partir de la formación y transformación de sus primeras organizaciones, específicamente del

\footnotetext{
${ }^{1}$ Hacemos referencia a la obra de Sergio Grez, Julio Pinto, Gabriel Salazar, Pablo Artaza, entre otros.

2 Scott, Joan. 1996. "El género: una categoría útil para el análisis histórico", en Lamas, Marta (Comp.). El género. La construcción cultural de la diferencia sexual, Ciudad de México, UNAM, p.289.

3 Núñez, Isabel. 2008. "El sujeto femenino en la pampa salitrera. Una mirada desde los estudios de género", en Diálogo Andino. Revista de Historia, Geografía y Cultura Andina nํ31, Arica, p.94.
} 
Centro Femenino Anticlerical Belén de Sárraga de Iquique. Proponemos que hombres y mujeres experimentaron de forma diferenciada el proceso de proletarización y las implicancias de la Cuestión Social que condujeron a su paulatina politización, en donde las diferencias estuvieron dadas por el factor de género en su interrelación con la condición de clase.

Fue este cruce lo que perfiló las formas de participación sociopolítica de las mujeres en el movimiento obrero $\mathrm{y}$, por tanto, el carácter que tuvieron las primeras organizaciones en Iquique. En ese sentido, se plantea como hipótesis que la participación sociopolítica de las mujeres en Iquique no respondió a hechos coyunturales y aislados, como tampoco a la influencia de los líderes obreros, sino que a un proceso de configuración identitaria operado entre las propias mujeres de sectores populares, en el cruce de los factores de clase y de género que orientaron la trayectoria de sus organizaciones. Ello se expresó en la diversidad de formas asociativas que generaron en el periodo estudiado, marcado especialmente por el mutualismo y el librepensamiento del Centro Femenino Anticlerical Belén de Sárraga.

\section{Contexto histórico}

El ciclo del salitre fue un extenso periodo de la historia regional, en el cual la producción de nitrato de soda en el desierto y su exportación a través de los puertos de embarque fue una de las principales actividades económicas del territorio tarapaqueño. Este periodo se extiende desde las primeras exportaciones de salitre desde el puerto de lquique a fines de la colonia hasta la paralización de Oficina Victoria, la última oficina salitrera tarapaqueña, en 1978. Esta época tuvo un subperiodo denominado ciclo de expansión del salitre, que comenzó bajo soberanía peruana en 1872 , debido a una serie de factores, entre ellos el agotamiento del guano, las nuevas tecnologías aplicadas a la industria y el predominio del salitre natural en el mercado internacional de fertilizantes. La era del auge salitrero en Tarapacá se prolongó durante medio siglo, hasta el fin de la Primera Guerra Mundial en $1918^{4}$.

El ciclo de expansión del salitre fue una época caracterizada por la modernización y la modernidad en todos sus sentidos: cultural, industrial, tecnológica, social e ideológica. En este periodo, se desarrolló una intensa industrialización de la pampa y de los puertos de embarque. La transformación económica atrajo migraciones laborales de diversa procedencia, en especial desde Chile hacia el Perú. La sociedad tarapaqueña de matriz colonial dio paso a una moderna sociedad regional caracterizada por procesos de larga duración como la proletarización de los sectores populares multinacionales y la conformación de una elite regional en la cual predominaron en primera instancia los empresarios peruano tarapaqueños, reemplazados tras la guerra por capitalistas europeos al amparo de las nuevas autoridades chilenas.

\footnotetext{
${ }^{4}$ González, Sergio.2016. “Las inflexiones de inicio y término del ciclo de expansión del salitre (1872-1919). Una crítica al nacionalismo metodológico" en Sergio González, Matamunqui. El ciclo de expansión del nitrato de Chile. La sociedad pampina y su industria, Santiago, RIL Editores, pp.209-232.
} 
Las exportaciones salitreras transformaron a la pequeña e irrelevante aldea colonial de Iquique en una ciudad en acelerado crecimiento y estrechamente vinculada al hinterland minero-industrial. Dicha transformación se aceleró vertiginosamente durante las décadas de expansión de la industria salitrera. Este proceso de urbanización fue uno de los principales fenómenos de esta época, en tanto que sostuvo una relación dialéctica con el desarrollo de la moderna sociedad regional. El desarrollo urbano del puerto consistió en la expansión y modernización de la ciudad, proceso caracterizado por conflictos, contradicciones y atravesado por la denominada cuestión social.

En este contexto, los sectores populares urbanos transitaron por una compleja etapa histórica en la que coexistió tanto la asimilación cultural al orden establecido como la autonomía para resignificar valores y representaciones sociales propias ${ }^{5}$. La experiencia de la modernidad para ellos no fue un proceso lineal, por el contrario, fue un proceso de desarrollo desigual que se caracterizó por una larga resistencia a la disciplina laboral y múltiples rebeldías cotidianas contra el orden urbano de la elite ${ }^{6}$. Los sectores populares urbanos habitaron densos barrios periféricos, compuestos por ranchos y conventillos dando origen a la problemática social urbana de la época. Los segmentos que efectivamente se proletarizaron y se constituyeron en alternativas clasistas modernas desplegaron también actividad huelguística y esbozaron sus propios cuestionamientos a la ciudad de las elites y el orden social que cobijaba.

La industria salitrera y sus actividades asociadas constituyeron la principal actividad económica en Chile y el fundamento de las finanzas fiscales. El desarrollo del movimiento obrero organizado tuvo sus inicios en los muelles de la ciudad de lquique, siendo un proceso ampliamente estudiado. La huelga general del 3 y 4 de julio de 1890 fue el bautismo de fuego de la clase obrera tarapaqueña y la primera movilización reivindicativa de masas de su tipo en la historia nacional. Antes y después de la huelga, nacieron en la ciudad una serie de organizaciones obreras que tuvieron como ejes la regeneración moral del pueblo, la instrucción de la clase trabajadora y la autogestión de las necesidades de la vida obrera en la ciudad. Estos sectores obreros ilustrados Ilegaron a proponer un modelo alternativo de ciudad, esbozando dicha propuesta a través de la prensa popular que proliferó en la primera década del 1900 y más allá. La indolencia de las clases dominantes y la extrema pobreza fueron particularmente crueles en Tarapacá y en la ciudad de lquique, como veremos a través de documentación respecto de las condiciones de vida de los sectores populares urbanos. El Estado oligárquicoliberal, "dócil, flexible pero a la larga frágil", permitió a sectores de elites múltiples negocios improductivos o espurios, a costa de las necesidades populares, erosionando aceleradamente

\footnotetext{
${ }^{5}$ Romero, Luis. 1990. Los sectores populares urbanos como sujetos históricos", Proposiciones №19, Ediciones SUR, Santiago, pp.268-278.

6 Pinto, Julio. 2002. “De proyectos y desarraigos: la sociedad latinoamericana frente a la experiencia de la modernidad", Revista Contribuciones científicas y tecnológicas, № 130, Santiago, pp. 95-113.
} 
la poca legitimidad del modelo económico y sociocultural, erosión de legitimidad denominada hacia centenario como "la crisis moral de la república"7.

Un botón de muestra de la pobreza urbana que aquejaba a los sectores populares, fue la mortalidad por enfermedades infectocontagiosas, la cual era superior no solo al promedio en las ciudades del país sino que también más alta que en las principales urbes del mundo. Por otro lado, el eterno problema de la vivienda obrera parecía no mejorar: en barrios populares de reciente desarrollo, como El Colorado, proliferaban viviendas cuyas características ligeras y primitivas contrastaban a la vista con la modernidad industrial y los espacios habitados $y$ frecuentados por la élite ${ }^{8}$.

En los siguientes cuadros pueden observarse el progresivo crecimiento demográfico de Iquique durante el ciclo de expansión del salitre, evidenciando la importancia que adquiere la ciudad respecto de la región; así mismo, estas cifras permiten establecer qué sectores de la ciudad comienzan a expandirse, en consonancia con la formación y masificación de una sociedad popular.

Tabla 1. Población de la provincia y la ciudad de lquique por subdelegaciones (Censos 1885-1907)

\begin{tabular}{|c|c|c|c|c|c|c|}
\hline Año & $\begin{array}{c}1 \text { Oo del } \\
\text { Ferrocarril }\end{array}$ & 29Aduana & $\begin{array}{c}\text { 3ode la Escuela } \\
\text { Santa María }\end{array}$ & $\begin{array}{c}4 \text { Q⿻ de } \\
\text { Cavancha }\end{array}$ & Total ciudad & $\begin{array}{c}\text { Provincia } \\
\text { de Tarapacá }\end{array}$ \\
\hline 1885 & 5.348 & 2.765 & 6.833 & 1.042 & 15.988 & 45.086 \\
\hline 1895 & 10.158 & 2.290 & 14.258 & 6.325 & 31.031 & 89.751 \\
\hline 1907 & 12.118 & 1.022 & 20.422 & 6.589 & 40.151 & 110.036 \\
\hline
\end{tabular}

Fuente: Elaboración propia en base a censos de 1885, 1895 y 1907.

La explotación salitrera en auge, junto al desarrollo urbano y demográfico, permitieron la dinamización de áreas industriales y el sector de servicios, los que incrementaron y diversificaron sus productos y prestaciones, a la vez que absorbieron la gran cantidad de mano de obra disponible. En este contexto, las mujeres iniciaron su inserción al trabajo asalariado en fábricas, talleres y establecimientos ${ }^{9}$, en tareas consideradas adecuadas a sus capacidades y a su género, lo cual derivó en la feminización de determinadas áreas como la industria manufacturera (especialmente textil, fabricación de vestuarios y procesamiento de alimentos), el servicio doméstico y el comercio, en que las mujeres marcaron una fuerte presencia.

\footnotetext{
7 Salazar, Gabriel. y Pinto, Julio. 1999. Historia contemporánea de Chile Tomo I. Estado, legitimidad y ciudadanía, Santiago, LOM Ediciones, p.38.

${ }^{8}$ Rodríguez, Manuel. 1913. El trabajo y la vida obrera en Tarapacá, Santiago, Oficina del Trabajo. Edición consultada: Iquique, Osar, 2017.

${ }^{9}$ Cabe destacar que previamente y de forma paralela, las mujeres generaron mecanismos de subsistencia, tanto en el hogar como fuera de él. Ver: Brito, Alejandra. 2005. De mujer independiente a madre, de peón a padre proveedor. La Construcción de Identidades de Género en la Sociedad Popular Chilena 1880-1930. Ediciones Escaparate. Concepción.
} 
La pujanza económica del periodo, no se tradujo en el mejoramiento de las condiciones de vida de las y los obreros, sino que se manifestó en profundas desigualdades sociales: viviendas insalubres, desajuste entre los altos costos de los bienes básicos de consumo y los bajos salarios, escasas garantías estatales en el acceso a salud y educación, precarias condiciones laborales y ausencia de una legislación que protegiese a las y los trabajadores. Frente a la cuestión social, el mundo popular manifestó su descontento y desplegó acciones tendientes a su solución, explica Julio Pinto que“[...] el paso del siglo XIX al XX marcó también la creciente autovisualización de los actores, sobre todo de los de extracción popular, como parte de una 'clase trabajadora' con intereses, problemas y aspiraciones compartidos, y como sujeto llamado a inaugurar nuevas formas de convivencia humana ${ }^{10}$.

Siguiendo a Pinto, esta identidad proletaria fue producto de un proceso sociocultural que le otorgó sentido al sujeto, transformándolo en un actor colectivo que se reconoció a partir del sentido de pertenencia, como también en relación a diferencias respecto de un "otro" representado por la oligarquía, la clase social fue el eje articulador de la autoafirmación del movimiento obrero, no obstante no resultó excluyente respecto de otros elementos identitarios, como la etnia o el género. Según Pablo Artaza, “[...] frente a las dificultades vividas, los sectores populares de la provincia venían experimentando a lo menos dos procesos paralelos: el de su constitución como movimiento social y el surgimiento de organizaciones populares que crecientemente tendrían a representarlo"11.

Esto explica la proliferación de organizaciones desde mediados del siglo XIX (entre ellas las primeras instancias de mujeres) y la relevancia que cobraron las ideas anarquistas y socialistas como factores ideológicos que impregnaron al movimiento obrero.

A lo largo del periodo, constantemente las organizaciones obreras hicieron llamados a las mujeres a sumarse a las luchas sociales. Conforme se extendían las ideas socialistas y anarquistas, y mientras los obreros adoptaban posiciones más radicales frente a la explotación, se hizo patente en la prensa obrera la reflexión respecto del rol de las mujeres en las transformaciones sociales. Por ejemplo, la Mancomunal de Obreros de Iquique aludía a la necesidad de forjar un futuro en base a la unidad entre hombres y mujeres, publicando habitualmente artículos que, de forma pedagógica, explicaban sus posturas en relación a la igualdad, la erradicación de las injusticias y a elevar la valoración social de la mujer.

En ello, podemos advertir la necesidad de esta organización por sumar a las obreras a sus filas, así lo manifiestan hacia 1907 señalando que "es de imperiosa necesidad que la mujer con su moralizadora acción y su gallarda presencia en las filas sociales ayude al obrero en el campo

\footnotetext{
10 Pinto, Julio. 2004. "Discurso de clase en el ciclo salitrero: la construcción ideológica del sujeto obrero en Chile, 1890-1912", en Revista de Historia Social y de las Mentalidades, año VIII vol. 12, № 2, Santiago, p. 133.

${ }^{11}$ Artaza, Pablo. 2006. "La mancomunal de obreros de lquique: su propuesta de vinculación entre movimiento social y politización popular. 1900-1909”, en Revista Espacio Regional, Vol. 1, №3, Osorno, p. 10.
} 
de la sociabilidad para el mayor éxito feliz de la cultura de los hijos del trabajo que desde hace varios años nos hemos propuesto vigorosamente impulsar" ${ }^{12}$. Por su parte, en 1911 el periódico El Grito Popular señalaba que:

"La democracia socialista ha fundado un concepto superior sobre la mujer y su condición: Es la hermana del hombre; su compañera en la lucha por la vida, así en el placer como en el dolor. Según la democracia socialista la mujer no es inferior al hombre, es simplemente diferente. El hombre es la mitad de una vida, mientras la mujer es la otra mitad. Ambos se completan estando unidos. Ambos son incompletos cuando viven separados. Es necesaria la unión para formar una existencia entera, un ser entero. [...] La lucha reivindicadora de los derechos humanos es, pues, comun para hombres y mujeres. [...] Por esto la mujer debe tomar participación, por su propia iniciativa, en los problemas sociales que hoy se discuten y que tienen relación con los sentimientos de reivindicación social. No debe esperar que se le invite. Debe tomar sitio, por si misma, en las filas del ejército que marcha creando una vida nueva, preñada de libertades y de buenos sentimientos ${ }^{13}$.

En estas interpelaciones a la población femenina, es interesante visualizar ciertos elementos en torno al género entre los organizadores obreros, por ejemplo, la tendencia a considerar a la mujer como una colaboradora cuya responsabilidad es sumarse a una lucha trazada por los varones en representación de la clase trabajadora en su conjunto:

"La mujer muestra cierta acritud á las ideas socialistas, y al hablarle de emancipación económica y política, rechaza nuestras exhortaciones francas y sinceras, rehusando una doctrina sana y viril, que ha de ponerla en el nivel social que debe ocupar... La mujer es infinitamente sentimental y egoísta. No le habléis de su igualdad de derechos hasta apoderaros de estos dos sentimientos porque cree por atavismo, sin duda, que su misión no está más allá de los que haceres domésticos"14.

La conquista de derechos sería entonces guiada por la avanzada proletaria a partir de una impronta paternal, es decir que las mujeres serían artífices de su liberación bajo la tutoría de la vanguardia obrera representada por los socialistas. Por otra parte, la participación sociopolítica de las mujeres se interpretaba positivamente como la adquisición de virtudes viriles y masculinas. Ello se expresó en variadas oportunidades a lo largo del periodo. Tomaremos como ejemplo las ideas de Salvador Barra Woll -líder del POS-cuando señaló, en 1913, que: "y estos miles de mujeres, de almas varoniles aunan su esfuerzo para arrancarse las cadenas que le aprisionan, que la oprimen, que la hacen desgraciadas y por esto luchan con denuedo y con

\footnotetext{
12 “Notas de la pampa”, El Pueblo Obrero (Iquique), 2 de julio de 1907.

13 "La mujer en la democracia socialista", El Grito Popular (Iquique) [en adelante EGP], 28 de abril de 1911.

14 "Sensibilidad de mujer", El Despertar de los Trabajadores (Iquique) [en adelante EDT], 27 de enero de 1912.
} 
valor desde el campo de las letras y desde la tribuna pública" ${ }^{15}$. Este recurso simbólico sería utilizado con recurrencia para elogiar a líderes destacadas, dando a entender que la lucha por la emancipación de la humanidad se comprendía en clave masculina.

Desde mediados del siglo XIX, las mujeres comenzaron a irrumpir en el espacio público reivindicando derechos como la educación en igualdad de condiciones entre hombres $y$ mujeres, así como también a enunciar el reclamo por el sufragio. El inicio del siglo XX estuvo marcado por la aparición a lo largo del territorio nacional de diversas organizaciones de mujeres, provenientes de todos los estratos sociales y con diversas perspectivas y objetivos, lo cual nos habla de la presión por ampliar los márgenes de la representación política:

"Los discursos y las acciones desarrolladas por las organizaciones de mujeres de principios del siglo XX estuvieron marcadas por la generación de prácticas políticas de tipo representativo que tenían como horizonte final la inclusión de las mujeres a través de la extensión progresiva de sus derechos, bajo el cuidado de que esta integración no afectara los roles tradicionales, sino que les permitiera contar con mejores herramientas para insertarse en la modernidad."16

Las primeras experiencias de participación sociopolítica de las obreras en Tarapacá se encuentran en el mutualismo. La primera organización de este tipo fue la Sociedad de Obreras de lquique, fundada en mayo de 1890, en medio de un convulso contexto social que desembocó en la primera huelga general en Chile, iniciada en Tarapacá.

El mutualismo basó sus acciones en la búsqueda de alternativas para hacer frente a las carencias de los sectores populares. María Angélica Illanes señala que "el cuerpo y su necesidad fue el factor predominante que aglutinó en esta etapa al pueblo"17. En el caso de las sociedades de señoras, ello se expresó en el ahorro colectivo que permitía entregar a las afiliadas atención médica de enfermedades, cuota mortuoria y sepultura en el mausoleo de la sociedad, financiamiento de escuelas nocturnas, acceso a actividades culturales, entre otras. A lo largo de casi tres décadas, el mutualismo fue una de las principales formas asociativas de las trabajadoras tarapaqueñas, existiendo a lo menos veinte de éstas en lquique entre 1890 y 1918. En sus acciones solidarias y colaborativas es posible identificar la embrionaria formación de una identidad basada en ser mujeres y trabajadoras, además de constituir una instancia de aprendizaje político a partir del reconocimiento de problemas compartidos en la doble dimensión de género y de clase, por tanto el mutualismo excede al objetivo de satisfacción de

\footnotetext{
15 "La mujer de hoy y la de un mañana cercano", EDT, 15 de febrero de 1913.

${ }^{16}$ Gálvez, Ana. (Ed.) 2021. Históricas. Movimientos feministas y de mujeres en Chile (1850-2020), Santiago, Lom Ediciones, p.22.

17 Illanes, María Angélica. 2003. Chile des-centrado. Formación socio-cultural republicana y transición capitalista (1810-1910), Santiago, LOM Ediciones, p. 311.
} 
carencias inmediatas, en palabras de Rodrigo Oteiza: "su interés por una SSM [sociedad de socorro mutuo] y no por otra personalidad jurídica, pasa porque esta forma les permite plegarse a una lucha social mayor, siendo esta orgánica una estrategia coherente con sus demandas de seguridad y previsión social" ${ }^{18}$.

\section{Sociedades de Señoras y Socorros Mutuos en Iquique $(1890-1918)^{19}$}

Existieron organizaciones populares de mujeres cuya emergencia supuso una interesante novedad en el lquique de fines del siglo XIX. Hemos detectado ejemplos notables que nos hablan de capacidad orgánica de características específicamente femeninas, en base a documentación inédita. Hacia mayo de 1891, funcionó una Sociedad de Profesoras, dirigida por la presidenta Desideria Quintanilla. Esta organización fue un notable antecedente femenino del profesorado organizado, previo a la experiencia sindical del magisterio. Aún nos falta rastrear más elementos en torno a este organismo que suponemos tuvo un rol interesante en la construcción social de la infancia y la organización del profesorado femenino. Esta agrupación tuvo el suficiente prestigio social como para dirigirse, en plena guerra civil, a la Honorable Junta de Alcaldes nombrada por las autoridades congresistas, para solicitar permiso para interrumpir las clases regulares y llevar al estudiantado a escuchar la retreta de la Compañía de Bomberos Zapadores ${ }^{20}$.

Ese mismo mes de mayo, emerge de los documentos otra importante organización semiformal de mujeres, quienes desde el pequeño comercio popular se congregaron para exigir su derecho a ejercer su oficio en tanto trabajo autónomo. La presencia del comercio femenino ambulante fue un fenómeno que se extendió en la misma medida que crecía aceleradamente la ciudad en las últimas décadas del siglo XIX. Como estrategia de supervivencia y autonomía femenina, esta actividad era frecuentemente mal vista por las elites administrativas, la policía y el comercio establecido. En mayo de 1891, un grupo de aproximadamente cincuenta mujeres firmaron un extenso reclamo contra una ordenanza persecutoria emitida por alcaldía en contra de las mujeres que vendían productos en plaza Condell y los alrededores del edificio de la Recova. Las firmantes solicitaban a la municipalidad dejar sin efecto el documento que formalizaba su erradicación del sector, basado en la supuesta falta de aseo, interrupción de tránsito y desórdenes producto de la venta no autorizada de bebidas alcohólicas. Achacaban estas acusaciones como falaces e inventadas por el comercio establecido, alegando que ellas, junto con pagar el permiso para ejercer su comercio, suponen un beneficio para los

\footnotetext{
18 Oteiza, Rodrigo. 2019. Mujeres obreras. Organización y sociabilidad en la sociedad de Socorros Mutuos Unión y Fraternidad de Obreras de Valparaíso 1892 - 1897, tesis para optar al grado de Magíster en Historia, Pontificia Universidad Católica de Valparaíso, p.59.

${ }^{19}$ Elaboración propia, en base a información proporcionada por la Oficina del Trabajo prensa obrera.

20 Archivo Histórico del Museo Regional de Iquique. Fondo Ilustre Municipalidad de Iquique. Vol.11. Alcaldía Municipal 1891, f.16, 26 de mayo de 1819.
} 
compradores por cuanto "les facilitamos a estos últimos con nuestra competencia el abaratamiento de los artículos de primera necesidad que espendemos" 21. A partir de esta experiencia, podemos establecer que las ideas de redención social que aludían -directa o indirectamente- a la situación de la mujer y su rol en la transformación de la sociedad, encontraron en lquique un terreno fértil, entre mujeres acostumbradas a diversos grados de autonomía y acción colectiva.

Tabla 2. Sociedades de Señoras y Socorros Mutuos en Iquique (1890-1918)

\begin{tabular}{|c|c|c|c|}
\hline Nombre de la Sociedad & Año de fundación & Dirección & $\begin{array}{l}\text { Cantidad de } \\
\text { socias }\end{array}$ \\
\hline Obreras de Iquique & 1890 & Sin datos & Sin datos \\
\hline Sudamericana de Señoras & 1891 & O’Higgins \#1200 & 273 \\
\hline Obreras Unión Fraternal & 1892 & Sin datos & Sin datos \\
\hline Obreras Sudamericana & 1893 & O’Higgins \#1283 & 180 \\
\hline Sudamericana de Señoras $N^{\circ} 1$ & 1893 & O’Higgins 202 & 252 \\
\hline Internacional Protectora de Señoras & 1893 & Zeggers \#93 & 150 \\
\hline Peruana de Señoras & 1896 & Wilson \#158 & Sin datos \\
\hline $\begin{array}{c}\text { Señoras Unión Fraternal y Socorros } \\
\text { Mutuos }\end{array}$ & 1897 & Bolívar \#181 & 150 \\
\hline $\begin{array}{l}\text { Progreso Social de Señoras y Socorros } \\
\text { Mutuos }\end{array}$ & 1897 & Juan Martínez \#60 & 90 \\
\hline $\begin{array}{l}\text { Unión Universal de Señoras y Socorros } \\
\text { Mutuos }\end{array}$ & 1899 & Amunátegui \#209 & 315 \\
\hline Chilena de Señoras y Socorros Mutuos & 1899 & Sin datos & Sin datos \\
\hline $\begin{array}{c}\text { Auxiliadora Chilena de Señoras y } \\
\text { Socorros Mutuos }\end{array}$ & 1900 & Barros Arana \#242 & 84 \\
\hline Filantrópica de Señoras & 1900 & Bolívar \#180 & 53 \\
\hline Liga de Obreras & 1901 & Sin datos & Sin datos \\
\hline Emancipación de la Mujer & 1901 & Juan Martínez \#194 & Sin datos \\
\hline Sociedad de Señoras №1 & 1901 & Sin datos & Sin datos \\
\hline $\begin{array}{c}\text { Internacional de Socorros Mutuos } \\
\text { Hermanas del Trabajo }\end{array}$ & 1901 & 18 de Septiembre \#846 & 162 \\
\hline Señoras Estrella del Universo & 1905 & Tarapacá \#166 & Sin datos \\
\hline Boliviana de Señoras & 1908 & Ramírez \#103 & 103 \\
\hline
\end{tabular}

Fuente: Elaboración propia en base a Boletín de la Oficina del Trabajo nำ, 2014, fojas 15 a 17; notas de prensa en periódicos El Despertar de los Trabajadores, El Pueblo Obrero, El Grito Popular.

21 Archivo Histórico del Museo Regional de Iquique. Fondo Ilustre Municipalidad de Iquique. Vol.11. Alcaldía Municipal 1891, ff.22-25, 22 de mayo de 1891. 
La huelga general de 1890 significó un impulso para el movimiento popular, produciéndose una acumulación de fuerzas y el surgimiento de una avanzada proletaria. Por otra parte, a partir de la interpretación de la masacre de la Escuela Santa María de lquique en 1907, se produjo en el movimiento obrero una radicalización de sus posturas clasistas y reivindicativas, es decir que en el periodo que va entre ambas huelgas operaron cambios relevantes. Destaca Sergio Grez que "si hasta fines del siglo XIX, la cultura, el proyecto y el ethos colectivo del movimiento popular organizado podía sintetizarse en la aspiración a la 'regeneración del pueblo', hacia la época del baño de sangre de la escuela Santa María, el movimiento obrero ya enarbolaba la consigna más radical de 'la emancipación de los trabajadores'”22, lo cual incidió en la diversificación de las formas de organización, cuyo hito más relevante sería la escisión del Partido Democrático de la tendencia liderada por Luis Emilio Recabarren, fundando el Partido Obrero Socialista (en adelante, POS) en 1912, en la ciudad de lquique.

En los meses previos a la división del ala socialista, los demócratas declaraban que "la mujer tiene derecho á la intervención política y social en el gobierno y la administración de las colectividades y a la libertad de su sexo" ${ }^{23}$. En esa misma dirección se publicaron artículos promoviendo los derechos femeninos en un sentido reivindicativo, de modo que el POS tenía a cuestas un bagaje político e ideológico en torno a la condición de las mujeres, ensayado durante décadas de organización obrera, que paulatinamente se complejizaría y profundizaría, especialmente gracias a la contribución de nuevas ideas surgidas desde las propias mujeres que se integraron a las luchas sociales vinculadas al POS. Recabarren fue un ferviente promotor de la integración de las mujeres en la lucha por su emancipación, dedicando cobertura periodística y reflexiones en relación a la "cuestión de la mujer".

Durante las dos primeras décadas del siglo XX, las principales instancias de mujeres continuaron siendo las sociedades mutuales, cuyas acciones -recogidas principalmente por la prensa obrera y la correspondencia con la Intendencia-se remitieron a los objetivos inmediatos de ahorro colectivo mediante eventos sociales y la instalación de bazares de venta de comidas y bebidas pro fondos de cada organización, decayendo la participación en actividades reivindicativas tales como mitines o manifestaciones. Por otra parte, en la década de 1910 se observa una disminución de la cantidad de afiliadas en sociedades mutuales, algunas de ellas declaran su liquidación y no se constata en los archivos la creación de nuevas sociedades.

22 Grez, Sergio. 2007. "1890-1907: De una huelga general a otra. Continuidades y rupturas del movimiento popular en Chile", en Revista Cyber Humanitatis no 41.4 Disponible en: https://web.uchile.cl/vignette/cyberhumanitatis/CDA/texto_simple2/0,1255,SCID\%253D21033\%2526ISID\%253D73 0,00.html (julio 2018).

23 "Sensibilidad de mujer", EDT, 27 de enero de 1912. 
Tabla 3. Afiliadas a Sociedades Mutuales vigentes 1914-1917.

\begin{tabular}{|c|c|c|}
\hline Sociedad & Afiliadas en 1914 & Afiliadas en 1917 \\
\hline $\begin{array}{c}\text { Unión Fraternal de Señoras } \\
\text { Internacional de Señoras Hermanas } \\
\text { del Trabajo }\end{array}$ & 150 & 30 (Por liquidar) \\
\hline $\begin{array}{c}\text { Progreso de Señoras } \\
\begin{array}{c}\text { Internacional Protectora de } \\
\text { Señoras }\end{array}\end{array}$ & 162 & 105 \\
\hline $\begin{array}{c}\text { Unión Universal de Señoras } \\
\text { Auxiliadora Chilena de Señoras }\end{array}$ & 150 & 319 \\
\hline Total & 815 & 80 \\
\hline
\end{tabular}

Fuente: Elaboración propia en base a Boletín de la Oficina del Trabajo №9, 1914, fojas 15 a 17; Archivo Nacional de la Administración, fondo Dirección del Trabajo vol. 58, 1917.

Es destacable que, desde la cultura obrera ilustrada, encarnada en el POS y sus dirigentes, se esgrimieron duras críticas a las sociedades de obreras durante esta década. El Despertar de los Trabajadores, denunciaba con profunda indignación diversas manifestaciones de cultura popular en las fiestas de fin de año de 1912. En particular el periódico socialista de Luis Emilio Recabarren se mostraba molesto con las sociedades obreras femeninas:

"han metido piano en casa, han llenado las estanterías de licores y han establecido la consabida rifa (...) y a la puerta se asomaba un grupo de juventud femenina que arrastraba hacia adentro a los varones como hembras ansiosas de macho. Entre el espectáculo que esas sociedades presentaban y el que presenta el prostíbulo no hay más diferencia, que el nombre; aún al prostíbulo se le puede perdonar porque ese es su medio de vida y que algunas se titulen hermanas del trabajo, a esas no se les puede perdonar" 24 .

En opinión del naciente movimiento socialista, las sociedades obreras se convertían en inútiles organismos funcionales a la ignorancia y embrutecimiento del pueblo, no comprendiendo que las necesidades de sus asociados en realidad eran: "más ilustración, más moralidad, más cultura, más hijiene y trabajo permanente en bien de los obreros que hoy forman en filas de sociedades que ningún bien, ningún provecho, ningún adelanto aportan a la obra emancipadora de la clase trabajadora" 25 .

\section{Nuevas experiencias de acción y participación sociopolítica}

A partir de la década de 1910, surgen nuevas organizaciones con un carácter reivindicativo mayormente definido, que denunciaron de forma categórica la opresión de las mujeres y en

\footnotetext{
${ }^{24}$ El Despertar de los Trabajadores, Iquique, 31 de diciembre de 1912.
}

${ }^{25}$ El Despertar de los Trabajadores, Iquique, 2 de enero de 1913. 
cuyos discursos se identificaban los fundamentos de dicha opresión, imbricando los factores de género y de clase de manera explícita. El socialismo, el anarquismo y el librepensamiento fueron las principales corrientes de ideas que nutrieron al feminismo obrero de esta década. Cabe destacar que lo anterior no implicó la desaparición del mutualismo ni la superposición de una estrategia organizativa por otra, sino que funcionaron de manera simultánea, en torno a objetivos distintos.

En esta década, la presencia de mujeres en actividades reivindicativas en Iquique comenzó a reactivarse, así lo atestigua la conmemoración del 1 de Mayo de 1911 convocada por el Partido Democrático, el cual: "había convocado al pueblo a una conferencia que se realizó en la gran sala de reunión de El Grito Popular en la noche a las 830 , con una concurrencia que llenaba pletóricamente el recinto; había 600 u 800 personas quizás, con buena y escojida representacion del sexo femenino y del mundo infantil" 26 .

Así mismo, surgieron figuras femeninas en la prensa obrera hablando con voz propia. Sin ánimos de centrarnos únicamente en mujeres destacadas o excepcionales, consideramos relevante detenernos en el rol que jugaron determinadas lideresas, para explicar un proceso más amplio y colectivo, que fue la formación de una identidad de género y de clase que guiaría el actuar sociopolítico de las mujeres de sectores populares. Según consta en El Grito Popular, una de estas mujeres fue Rebeca Barnes, quien con solo 14 años intervino en la conferencia del 1 de Mayo de 1911, para hacer énfasis en la importancia de que las mujeres luchasen por sus derechos:

“[...] levanto mi débil voz, en nombre de mi sexo y de mi edad. Si los obreros con justa razón hacen sus peticiones, defendiendo sus derechos pisoteados, también las mujeres tenemos muchos y altos ideales y derechos que nos corresponden y que muy poco nos han preocupado. Hai personas que creen que la mujer es simplemente la esclava del hogar o que solo está llamada a ser lavandera, cocinera, conductora, etc., etc. No, y mil veces no! El Creador, en su ilimitada sabiduría, nos dotó de igual inteligencia, como elevada mision, pues la mujer bien educada sabrá desempeñarse con acierto si se le educa y no se le usurpan sus derechos. Nuestras madres, son las que forjan nuestro carácter y si la madre es ignorante, sus hijos serán iguales [...] No olvidéis, que la cuna de la verdadera democracia, bien comprendida, tiene su principio sólido en el regazo de la madre." ${ }^{27}$

Esta alocución marca un precedente en tanto que surgen elementos ausentes en el lenguaje político de las décadas anteriores. En primer lugar, pone de manifiesto la vulneración de derechos específicamente de mujeres y la necesidad de reivindicarlos; en segundo lugar, critica

\footnotetext{
26 “El $1^{\circ}$ de Mayo, la manifestación en Iquique", EGP, 3 de mayo de 1911.
}

27 “El 1 de Mayo, la manifestación en Iquique", EGP, 3 de mayo de 1911. 
la posición subalterna de las mujeres en la sociedad de su época, cuestionando el vínculo supuestamente natural con los cuidados domésticos y con determinados oficios que se encontraban altamente feminizados, haciendo hincapié en la igualdad de condiciones intelectuales entre hombres y mujeres.

Finalmente, destaca la alusión a la función materna como responsabilidad social de las mujeres, pero no solo en cuanto a la reproducción de la familia sino que a los fundamentos mismos de la democracia y, por ende, del socialismo. En lo sucesivo, Rebeca Barnes intervino de forma permanente en los más importantes actos y ceremonias obreras. Otro hecho significativo, fue la presencia de Teresa Flores como única mujer en la sesión de fundación del Partido Obrero Socialista en 1912, siendo también una de las dirigentes más destacadas del periodo.

A partir de 1911 se detecta participación de mujeres en actividades e instancias organizativas de carácter reivindicativo, ejemplo de ello es el conflicto suscitado entre las lavanderas del Ejército y la administración. En diciembre de 1912, El Despertar de los Trabajadores publicó una serie de denuncias sobre irregularidades hacia las lavanderas (maltratos verbales, retraso del pago de salarios, prestaciones extraordinarias como servir en el domicilio del administrador y lavar de ropa no institucional de jefaturas del Ejército). El 4 de enero de 1913 estas lavanderas paralizaron sus labores y elevaron un reclamo, siendo posteriormente despedidas:

"Las obreras que en virtud de reconocidos malos tratos habían abandonado sus labores i se presentaron en queja á la superioridad militar han sido despedidas definitivamente del trabajo, recibiéndose en su lugar á nuevas obreras inespertas en ese trabajo. La causa de la suspensión no ha sido motivada por considerar injustas las quejas de dichas obreras, puesto que estas quejas han sido debidamente comprobadas en presencia del coronel [...] La superioridad militar suspendió á cuatro obreras que el administrador señaló como las denunciantes de los párrafos publicados por nosotros $\mathrm{i}$ las otras tres que no estaban señaladas como las primeras, tuvieron la suficiente dignidad para manifestar que tampoco ellas irían al trabajo si no iban las cuatro primeras" 28 .

Consideramos que el castigo que se impuso a las trabajadoras responde a que estas mujeres reclamaron mediante la denuncia pública y recurrieron a la paralización de sus labores, transgrediendo la docilidad y sumisión que se consideraban características de la mano de obra femenina, por tanto se les aplicó una sanción ejemplificadora. Es interesante constatar el actuar colectivo de las siete operarias de la lavandería, tanto de quienes denunciaron los hechos como de aquellas que paralizaron sus labores ante el despido de las denunciantes. Si consideramos la

28 "Lo de la lavandería del Ejército. Operarias despedidas", EDT, 4 de enero de 1913. 
ausencia de acciones de reivindicación laboral entre las mujeres durante el periodo estudiado, este hecho nos parece altamente significativo, siendo por lo demás la primera expresión de huelga de trabajadoras documentada en la prensa obrera tarapaqueña. Cabe señalar, que a nivel nacional esta década estuvo también marcada por la aparición de sociedades de resistencia y actividad sindical entre las obreras.

\section{Articulación sociopolítica y librepensamiento: el Centro Femenino Anticlerical Belén de Sárraga de lquique}

En 1913, la preocupación de los líderes obreros y de las propias mujeres por la educación femenina como mecanismo de adelanto social, coincidió con la visita a Chile de la conferencista Belén de Sárraga, tras la cual nació un nuevo tipo de organización basado en el librepensamiento, el anticlericalismo y el feminismo, complejizando así el espectro discursivo de las tarapaqueñas respecto de su propia condición. La visita de Sárraga, ampliamente documentada en diversas investigaciones ${ }^{29}$, es sindicada como uno de los hitos más importantes para el movimiento de mujeres en el siglo XX, tanto por su impacto a nivel organizacional, como por su contribución a la progresiva elaboración de una postura crítica en torno a la subordinación de las mujeres.

El contexto estudiado, estuvo marcado por la disputa en torno a la separación de la Iglesia y el Estado, debate que no sólo se dio entre sectores de la elite, sino también tuvo ecos en movimiento obrero que adoptó posiciones laicas. Así, el anticlericalismo estuvo presente de forma incipiente desde inicios del siglo XX, expresado en la crítica esgrimida hacia la iglesia y su influencia retardataria entre las clases populares, coadyuvando a la dominación de las conciencias en favor de la explotación capitalista, según Ana María Carrasco:

"El contexto latinoamericano en el cual Belén inicia su recorrido, se caracteriza por encontrarse en gestación un importante pensamiento liberal progresista que cuestionaba las posturas conservadoras de la Iglesia Católica, la que en esos tiempos, además de mantener un fuerte control sobre la enseñanza, los casamientos, nacimientos, etc., imponía un comportamiento ético y moral que afectaba con mayor fuerza a las mujeres. Este clima de presión y restricción permite que se genere un embrionario movimiento femenino que adquiere gran protagonismo social, aun cuando todavía no desarrolla una clara conciencia de demandas de género" ${ }^{\prime 30}$.

\footnotetext{
${ }^{29}$ Ver Vitale, Luis y Antivilo, Julia. 1999. Belén de Sárraga: precursora del feminismo hispanoamericano, Santiago, Editorial CESOC; Gaviola, Edda et al. 1986. Queremos votar en las próximas elecciones: historia del movimiento femenino chileno 1913-1952, Santiago, Editorial La Morada, pp. 27-34. Venegas, F. Víctor Domingo Silva Endeiza: una vida sin detenciones (1882-1960), Consejo Nacional del Libro y la Lectura, Limache, p.110.

${ }^{30}$ Carrasco, Ana María. 2014. "Remolinos de la pampa. Industria salitrera y movimientos de mujeres (1910-1930)", en Revista Estudios Atacameños, №48, San Pedro de Atacama, p. 167.
} 
De esta forma, al indagar sobre las razones esgrimidas sobre el atraso político y la inferioridad social de las mujeres, estos sectores concluyeron que la influencia religiosa en distintos aspectos de la vida (la educación, la familia y la moral pública) sustentaba dicho estado de cosas. Rebeca Barnes intervino en una conferencia organizada por El Despertar de los Trabajadores semanas antes de la visita de Belén de Sárraga, en la cual:

“[...] discertó un tema sobre la educación moral que debe difundir el hombre en un hogar para que no ocurra el triste caso, tan común hoy, de que la mujer obedece ciegamente cuanta estupidez le inculca el fraile y desprecia lo que su compañero, su marido, con quien comparte su vida, le pueda aconsejar, ofreciéndose así á los hijos una educación inmoral por culpa de la intromisión indebida de la iglesia en el hogar"31.

Es interesante constatar las diferentes posturas que Rebeca Barnes presenta entre su intervención de 1911 y la recién citada en 1913 en relación a la fe: en la primera, alude a Dios como creador de la humanidad (suponiendo una adscripción al cristianismo), mientras que en la segunda apela a la educación laica, ello puede ser reflejo de la creciente influencia del anticlericalismo entre las mujeres de sectores populares.

La prensa obrera destacó la nociva influencia del clero entre la población femenina, sin embargo se argumentaba que la consecuencia de ello no generaba únicamente perjuicios para la libertad de la mujer sino que de toda la familia, puesto que una cierta debilidad natural de las mujeres determinaría su mayor inclinación hacia las ideas religiosas, lo cual, según denunciaban, era aprovechado por la iglesia como mecanismo indirecto de dominación de la familia proletaria completa. Con lo anterior, se hacía cómplice pasiva a la mujer de la esclavitud de la clase trabajadora y se asume, a su vez, que los varones son víctimas del actuar irracional de sus compañeras, relativizando así su corresponsabilidad sobre el problema de la religión:

“La mujer tiene generalmente el cerebro más débil, más impresionable y la iglesia ha sido astuta al procurar apoderarse especialmente de la mujer, para de esta manera apoderarse del niño y del hombre. No permitamos, liberales de verdad, que la iglesia tenga sus propios representantes en nuestro mismo hogar, y que convierta a cada liberal en un manequí no manejado por su conciencia y su razón, sino por el clero soberbio que ha logrado aprisionar el corazón de la mujer para dominar al hombre"32.

\footnotetext{
31 “A beneficio de El Despertar. Nuestra conferencia del sábado", EDT, 11 de febrero de 1913.

32 "Empleados y trabajadores", EDT, 11 de marzo de 1913.
} 
Por tanto, en el contexto previo a la visita de Belén de Sárraga se había instalado la necesidad de educación laica para las mujeres y restar poder a la Iglesia católica en la sociedad, como elementos claves para la emancipación de las y los trabajadores.

Ahora bien, si esta constituía una demanda transversal de clase, ¿por qué posteriormente las mujeres deciden agruparse solo entre ellas mismas? Consideramos que existen variadas aproximaciones a este fenómeno, muchas conjeturas e incertidumbres. A nuestro juicio, sin embargo, ello dice relación con el proceso de articulación autónoma desarrollado en las décadas previas bajo diversas lógicas -analizadas anteriormente-, apoyando nuestra hipótesis respecto de la configuración de una identidad que entrecruza la clase y el género para articular la acción sociopolítica.

En su activismo anticlerical, Belén de Sárraga recorrió parte de Sudamérica realizando conferencias, lo cual aportó a la circulación de ideas entre los sectores liberales progresistas y, por supuesto, entre las mujeres, de distintos países. Los postulados de Belén de Sárraga abarcaban distintas dimensiones de la cuestión social. En lo político, transitaban entre la tradición anarquista y socialista, en sus conferencias hacía referencia tanto a las problemáticas de la clase trabajadora, como a las injusticias específicas que afectaban a la mujer desde un cuestionamiento a las relaciones sociales, poniendo especial énfasis en la importancia de su participación social y su educación.

Recabarren y Teresa Flores invitaron a la conferencista a lquique, recorrieron también la pampa salitrera, prolongando su estadía entre marzo y julio de 1913. Su visita concitó gran expectación entre la población local, sin distinción de clases: mientras que para el movimiento obrero su figura irradiaba sabiduría para contribuir al adelanto cultural de la clase trabajadora, para los sectores conservadores y la Iglesia representaba una amenaza al orden social con el consiguiente riesgo de generar un estallido popular que atentara contra la propiedad. Lo anterior se tradujo en una ardua campaña mediática para desacreditar a la conferencista, según los redactores de El Despertar de los Trabajadores:

“[...] Los clericales hicieron activa propaganda desde el púlpito y el confesatorio para anatematizar al débil espíritu de la pobre mujer y hacerla que hiciera activa propaganda entre sus amigas, para evitar que la mujer fuera á la conferencia anunciada y las que después daría. Cumpliendo esta consigna la mujer fanática comenzó su obra desquisiadora inventando calumnias estúpidas y groseras que la pluma se resiste á describir" ${ }^{\prime 3}$.

La primera conferencia se dictó el 11 de marzo en el Teatro Municipal, asistiendo alrededor de 800 personas, mientras las autoridades locales instalaban tropas del regimiento

33 “Campaña inútil”, EDT, 11 de marzo de 1913. 
Carampangue para resguardar la ciudad, especialmente el edificio de la Vicaría, ante posibles desórdenes y motines producto de la agitación contra el clero que se desprendía de su mensaje. Durante su estadía, Sárraga dictó nueve conferencias en lquique y distintos puntos de la pampa, varias de las ellas culminaron con manifestaciones espontáneas del público asistente que terminaban en completo orden, según señala la prensa. Los títulos de las conferencias fueron: "Trayectorias humanas", "La mujer como entidad social", "La familia", "La moral", "Los pueblos y las congregaciones religiosas", "El problema de la educación", "El jesuitismo y el porvenir de América", "Clericalismo y democracia" y "La iglesia y el trabajo" 34 . El POS y especialmente las mujeres vinculadas a él, como Barnes y Flores, convocaron a las mujeres de lquique a asistir a todas las veladas, expresando la confianza en que el mensaje de Sárraga podría influir en el elemento femenino para despojarlo de la principal ideología que coartaba su adhesión a las ideas progresistas:

“Creemos también que la mujer, esa pobre y desgraciada mujer, que aun no concibe que hay para ella toda una gran revolución igualitaria del derecho, decimos cuando sepa que hasta ahora no ha sido sino el juguete vulgar de la iglesia y del hombre, cuando todo esto lo sepa por boca de una intelijente mujer que todo lo ha estudiado, entonces la mujer se elevará y ocupará el Trono de la Ciencia para de allí dirijir la marcha augusta del progreso de la humanidad y velar por el resurjimiento del sexo femenino a la verdad razonada. ¡Acudid, pues, mujer! a las conferencias a recojer la sabia bienhechora que te librará de los prejuicios fanáticos que destruyen tu felicidad" 35 .

Como se mencionó, tras estas conferencias se conformaron nuevas instancias asociativas que reflejaron el impulso cobrado por la participación sociopolítica de las mujeres a lo largo de décadas, tendiendo a la definición de ideas y estrategias de acción en pos de la emancipación de las mujeres. Concordamos con Julia Antivilo, quien señala que:

"Es significativo destacar que en Chile la influencia del pensamiento y la praxis política de Belén de Sárraga conformó el hito para hablar de movimiento de mujeres y movimiento feminista en Chile pues los Centros Femeninos de Librepensadoras y Anticlericales Belén de Sárraga son la consolidación de un proceso de génesis del movimiento de las mujeres y el movimiento feminista integrando el movimiento social de las primeras décadas del siglo $X X^{\prime \prime 36}$.

\footnotetext{
${ }^{34}$ Carrasco, Ana María. 2014. "Remolinos de la pampa", p. 168.

35 “La señora Belén de Sárraga y sus conferencias", EDT, 6 de marzo de 1913.

36 Antivilo, Julia. 2019. "Crónica de un torbellino libertario en América Latina. Belén de Sárraga (1906-1950)", en Revista Historia de las Mujeres, año XX no 191. http://www.cemhal.org/anteriores/2019_2020/24Antivilo.pdf (Consultado en octubre 2020).
} 
El 10 de abril de 1913, mientras Sárraga se encontraba de gira por la pampa, Teresa Flores anunciaba la creación de un centro de mujeres librepensadoras en Antofagasta e invitaba a replicar esta acción en lquique "á las mujeres de todas las edades que quieran adherirse á esta idea" ${ }^{37}$. Posteriormente, el 17 de abril, se oficializó la creación del Centro Femenino Anticlerical Belén de Sárraga de Iquique (en adelante, el Centro) en una reunión que congregó aproximadamente a sesenta mujeres, entre ellas Teresa Flores, María Castro, Margarita Zamora, Margarita Sanhueza, Francisca v. de Carrizo, María Carrizo de Mena, Zoila Zepeda de Toro, Juana Alvarado de Guzmán, Ana Guzmán, Juana A. de Villalba, Luisa de Zabala, Nieves P. de Alcalde, Julia de Gómez, Justa Barrera, Herminia Robles, Teresita Véliz, Pabla R. de Aceituno, Ilia Gaete, Adela de Lafferte, Rosario de Barnes y Rebeca Barnes.

Los estatutos de este Centro, publicados por El Despertar de los Trabajadores, expresan las principales orientaciones y acciones a desarrollar, en su misión emancipadora:

"Art. $1^{\circ}$ Este centro se compone de mujeres que voluntariamente y solo por amor á la verdad, se comprometen á no tener en lo sucesivo ninguna relación directa ni indirecta con el clericalismo y sus instituciones.

Art. $2^{\circ}$ Todas las mujeres que compongan este Centro se comprometen á propagar estos bienhechores pensamientos por medio de visitas domiciliarias á sus amigas, invitándolas á conferencias, exhortándolas á leer y a estudiar y buscar la verdad.

Art. $3^{\circ}$ Las madres de familia que ingresen al Centro educarán sus hijos dentro del mas alto sentimiento de libertad y de verdad y ajenos á todo sentimiento clerical.

Art. $4^{\circ}$ Las jóvenes que ingresen a este Centro cuidarán al formar su hogar, que el compañero que elijan sea un verdadero y firme libre pensador.

Art. $5^{\circ}$ Todas las que compongan este Centro, á la medida de sus fuerzas, procurarán propagar el librepensamiento y aumentar el número de afiliadas.

Art. $6^{\circ}$ Para el sostenimiento del Centro y la propaganda de sus ideales, cada socia pagará una cuota de un peso mensual.

Art. $7^{\circ} \mathrm{El}$ Centro efectuará á lo menos una velada mensual para divulgar y popularizar sus ideales. Igualmente tomará parte en toda clase de conferencias, comicios ú otros actos instructivos." ${ }^{38}$

Tanto en lquique como en los centros que posteriormente se fundaron en los pueblos de Lagunas y Negreiros, adhirieron una importante cantidad de esposas e hijas de dirigentes obreros. Consideramos que la filiación familiar de las mujeres movilizadas no debe reducir su participación sociopolítica a la mera existencia de un vínculo con un militante varón, restando

\footnotetext{
37 “La mujer en acción también se emancipará”, EDT, 10 de abril de 1913.

38 “El Centro Femenino Anticlerical Belén de Sárraga se funda gallardamente", EDT, 19 de abril de 1913.
} 
autonomía a sus acciones y eclipsando la trayectoria de organización existente en lquique desde 1890. Si bien el influjo de las corrientes socialista y anarquista es innegable y que los dirigentes obreros promovieron su organización, no es posible explicar la experiencia de estas mujeres y su apropiación de las ideas en circulación solamente en base al llamado a la acción que les hicieran los varones. Consideramos, por tanto, relevante visibilizar la actuación de las mujeres del Centro Belén de Sárraga de Iquique para evitar interpretaciones fragmentarias basadas ya sea en vínculos familiares o en la intervención de los varones como causa de la organización femenina, hacia una interpretación integral que destaque la imbricación de las problemáticas de género con las de clase en la configuración del movimiento de mujeres en este periodo.

Las principales acciones de estos centros correspondieron a eventos sociales, participación en mitines obreros, organización de veladas y conferencias cuyos objetivos eran la educación y el debate en torno a las problemáticas de la mujer y la clase obrera en su conjunto, a partir del anticlericalismo y el librepensamiento como herramientas para la emancipación. En sus reuniones semanales, se realizaban sesiones de lectura y diálogo, clases de canto para la formación de un coro, además de ajustes orgánicos. Este Centro hizo su primera aparición pública en la conmemoración del 1 de mayo de 1913, obteniendo muy buena acogida por parte de la concurrencia. A lo largo de sus años de funcionamiento, las socias se hicieron presentes en distintos actos organizados por el POS, volviéndose recurrentes las intervenciones de algunas socias que cobraron popularidad y admiración como Teresa Flores, Rebeca Barnes, Pabla R. de Aceituno, Teresita Véliz, entre otras.

Posteriormente a la creación del Centro de Iquique, se fundó otro en el pueblo de Lagunas, tras una gira realizada en dicha localidad por las jóvenes Teresita Véliz y Rebeca Barnes (ambas bordeando los 15 años), oportunidad en la cual realizaron veladas en distintas oficinas salitreras que concitaron entusiasmo y admiración, dada la corta edad de sus conferencistas. Cabe destacar que, posteriormente, este activismo le costó a Rebeca Barnes su expulsión del Liceo de Niñas de Iquique. Así lo expuso su padre, David Barnes, en la prensa:

"Era nada menos para esponerme que la H. J. de V. [Honorable Junta de Vigilancia] había hace cuatro meses, ordenado la espulsion de mi hija, J. Rebeca, porque la consideraban inmoral para estar en ese establecimiento de instruccion y que ese indeclinable acuerdo, era debido a la acusacion o quejas de varias familias hecha á la Junta con respecto a mi hija." ${ }^{39}$

Otro tipo de acción que pudimos detectar en el primer año de funcionamiento del Centro, fue la distribución de propaganda anticlerical y socialista en medio de fiestas religiosas, como sucedió en la procesión de Corpus Cristi a fines de mayo de 1913, en la cual participó un grupo de jóvenes resultando detenidas dos de ellas, quienes fueron puestas en libertad ante la presión

39 “Carta abierta”, EDT, 24 de junio de 1913. 
pacífica de una multitud de personas. Este hecho fue catalogado por los socialistas como una abierta provocación por parte del clericalismo, acusando además, que algunas señoras católicas que participaban de la procesión habrían agredido a este grupo de jóvenes pinchándolas con alfileres.

Un sello característico de la sociabilidad obrera en esta década, fue la actividad artística como herramienta pedagógica y política, con el objetivo de promover la cultura obrera ilustrada. En esa dirección, se formó el grupo teatral Arte y Revolución, en mayo de 1913, contando con la participación de algunas socias del Centro, incluida su presidenta, Teresa Flores. Este núcleo cobró relevancia, dado que amenizaban las actividades de agitación y conferencias en que se difundían las ideas socialistas y el librepensamiento con representaciones teatrales, además de las intervenciones musicales del coro obrero, coro del Centro Belén de Sárraga, una estudiantina obrera y las declamaciones de poesía que, generalmente, estuvieron a cargo de niñas y mujeres jóvenes.

En su conjunto, estas expresiones artísticas abordaban temáticas de gran sensibilidad como la miseria obrera, el problema del alcoholismo, los abusos clericales, el abandono de los padres de familia, entre otros. Se destaca, por tanto, la articulación entre el Centro y las organizaciones que gravitaban en torno a las ideas socialistas, las cuales se complementaban y potenciaban en sus actividades.

En su primer año de funcionamiento, el Centro "ha participado en 68 actos, que equivalen a más de uno por semana" ${ }^{40}$. Se había proyectado la edición de una revista elaborada por sus socias dirigida al público femenino; sin embargo, este proyecto no parece haber visto la luz, a excepción de un breve folleto editado por El Despertar de los Trabajadores llamado Voces Femeninas, que recopilaba discursos de la socia Jenoveva E. Cabello y que fue puesto en circulación en Iquique y la pampa a fines de abril de $1914^{41}$. Lamentablemente no existen copias adjuntas ni se reproduce su contenido en las ediciones de periódicos obreros.

La prensa femenina en Chile se remonta al siglo XIX, en el caso de las mujeres de sectores populares, sus publicaciones pioneras fueron La Alborada y La Palanca, creadas durante la década de 1900, señala al respecto Claudia Montero que:

"La prensa política de mujeres tiene la especificidad de ser producida por un colectivo organizado que posee un discurso político, génesis del activismo femenino. A grandes rasgos, este tipo de prensa primeramente es un medio de expresión de ideas, vocero de las

\footnotetext{
40 "El primer aniversario del Centro Femenino Anticlerical Belén de Sárraga", EDT, 21 de abril de 1914.

41 "Voces femeninas", EDT, 23 de abril de 1914.
} 
opiniones y reflexiones para difundirlas al público general. Pero también estos medios son concebidos como un espacio de construcción de movimiento y formación política." ${ }^{42}$

En este sentido, resulta llamativo que en Iquique, pese a la algidez del movimiento social y político, no se haya producido prensa de mujeres. Elizabeth Hutchison, recalca esta particularidad teniendo en consideración que esta provincia fue el nicho político de Recabarren, quien contribuyó a la movilización de los sectores femeninos ${ }^{43}$, a ello podemos añadir que dado el auge que cobró el Centro y su constante agitación hacia el público femenino es curioso que no se materializara la creación de un periódico propio, para operar en el sentido que describe Montero. Por otra parte, destacamos que si bien en El Despertar de los Trabajadores (y en menor medida, en otros periódicos de la región) era recurrente la inserción de artículos alusivos a las mujeres y su movilización, por lo general fueron aportes realizados por varones o transcripciones de discursos de las socias del Centro, de modo que el acceso que tenemos a la palabra de las mujeres organizadas en esta etapa es solo a través de discursos que fueron reproducidos (e intermediados) por los editores de la prensa obrera.

Otra expresión de participación sociopolítica, fue la inclusión de dos delegadas del Centro Femenino a la Cámara del Trabajo, entidad multigremial para la defensa de los derechos del proletariado. Incluso una de ellas, Julia de Gómez, fue designada a la mesa directiva de dicha entidad en calidad de vocal de la provincia de Tarapacá. En octubre de 1913, se produjo un quiebre político entre fracciones al interior del POS que tendría como implicancia para al Centro, la petición de su salida de la Cámara del Trabajo, la cual fue explicada por el núcleo socialista como una traición de sus contendientes en contra de la obra regeneradora que realizaba la agrupación femenina ${ }^{44}$. No obstante, el argumento esgrimido por la contraparte era que la Cámara del Trabajo debía estar compuesta por gremios de trabajadores, en lo cual el Centro no encajaba, dado que sus fines no eran la representación ni las reivindicaciones laborales (al menos de forma directa).

Esta coyuntura significó además un quiebre entre las socias del Centro, produciéndose la renuncia de algunas de las fundadoras y principales oradoras como Juana Villalba, Rosario de Barnes, Teresa Veliz y Rebeca Barnes. Esta escisión no impactó en la capacidad de acción del Centro, pues contaba todavía con más de cuarenta socias, a las que se unirían constantemente nuevas adherentes, de esta forma se dio continuidad a las veladas mensuales y a la activa participación en la sociabilidad obrera vinculada al POS.

\footnotetext{
42 Montero, Claudia. 2018. Y también hicieron periódicos. Cien años de prensa de mujeres en Chile 1850-1950. Santiago, Editorial Hueders, p. 85.

43 Hutchison, Elizabeth. 2006. Labores propias de su sexo. Género, políticas y trabajo en Chile urbano 1900-1930. Santiago, LOM Ediciones, pp. 79-120.

44 "Centro femenino recibe un colazo de los azules", EDT, 2 de octubre de 1913.
} 
Hacia mediados de 1914, comenzaron a sentirse los efectos de la Primera Guerra Mundial sobre la economía local. Ante las dificultades sociales y económicas para proseguir el activismo, el Centro Belén de Sárraga se dedicó a realizar bazares y veladas en beneficio propio, del POS y de la imprenta de El Despertar de los Trabajadores.

Por otra parte, se marcó presencia en mitines convocados en defensa de los obreros cesantes, fomentando la participación de las mujeres: "las mujeres que somos las que más de cerca conocemos y observamos el debarajuste económico del hogar debemos preocuparnos de estos asuntos, con todo el interés del que quiere ver mitigar la afliccion que ha causado gran catástrofe financiera, producida por el violento sacudon guerrero" ${ }^{45}$. Instalando así, en el sentido común de las mujeres de la clase obrera, las formas en que les afectaba la crisis y, por tanto, lo necesario de su participación en las movilizaciones a partir de su rol en el hogar. El Centro elaboró también un petitorio dirigido al gobierno y al municipio, en el que solicitaban mejoras a la condición de la familia obrera, especialmente en la regulación de los establecimientos de expendio de bebidas alcohólicas, identificando al alcoholismo como un daño para la economía doméstica.

En este contexto de crisis económica y agitación social, la acción socialista da cuenta de dos intentos de potenciar la organización gremial de las obreras. La primera fue la inclusión de mujeres al gremio de zapateros existente en Iquique, pasando a denominarse Gremio de Zapateros y Aparadoras. La segunda fue el llamado realizado por la Sociedad de Oficios Varios con miras a formar una sociedad de resistencia de trabajadoras: "La Sociedad de Oficios Varios invita para mañana a todas las obreras para que se organicen en sociedad Defensa del Trabajo... Es preciso que las obreras se organicen para disminuir siquiera un poco la brutalidad de la esplotacion" ${ }^{46}$, el inserto se dirigía explícitamente a costureras, lavanderas y aplanchadoras. El resultado de dicha reunión parece haber sido exitoso, se dio cuenta días más tarde que:

"El viernes 6 del pte. se congregaban una multitud de obreras deseosas de mejorar su triste condición de esclavas, en el espacio local de los sindicatos obreros, a invitación de la Sociedad de Oficios Varios cuyo fin es el de organizar á todos los desheredados del patrimonio universal, en sociedad de resistencia, sin distincion de nacionalidad ni sexo. [...] Después de un lijero cambio de ideas, se nombró un Comité compuesto de cinco compañeras una Secretaria una Tesorera y tres vocales ésta organizacion recien constituida se le dio el nombre de "Federación de Obreras en resistencia", la que agrupará en su seno á todas las obreras de las diferentes ramas de la actividad humana"47.

\footnotetext{
45 "El centro femenino anti-clerical", EDT, 2 de septiembre de 1914.

46 "Para mañana", EDT, 5 de febrero de 1914.

47 "Grandioso triunfo de oficios varios", EDT, 10 de febrero de 1914.
} 
Estas iniciativas nos parecen relevantes dado que contrastan con la consideración del trabajo de la mujer como actividad secundaria y que su condición de clase estaría dada por su vínculo con el obrero. En estos llamados se observa un giro que releva a la mujer a partir de su condición de proletaria. Por otra parte, Hutchison plantea que la apelación a la organización laboral femenina por parte de los líderes obreros buscaba concitar fuerzas contra la baja de los salarios en general en determinados momentos de crisis, no como una política constante, de modo que:

"[...] particularmente cuando la presencia de las mujeres trabajadoras en la fuerza laboral manufacturera se hizo una realidad, las organizaciones obreras animaron a las mujeres a organizarse por sí mismas y a presionar por salarios más altos, para atenuar la presión a la baja de los salarios industriales masculinos causada por la disponibilidad de una enorme y barata reserva laboral femenina" 48 .

Con posterioridad a este anuncio, no se menciona en la prensa a esta federación de obreras y el Gremio de Zapateros y Aparadoras muestra escasa actividad, manteniéndose la preponderancia de las organizaciones no laborales como forma asociativa de mujeres.

Hacia fines de 1914, se percibe en el Centro un decaimiento del funcionamiento interno, problemas administrativos y una periódica rotación de su directiva. Además, según el Boletín de la Oficina del Trabajo, esta organización contaba solamente con cincuenta socias ${ }^{49}$, mientras que las ocho sociedades mutuales vigentes tenían entre 85 a 315 socias cada una, con un total de 1.377 afiliadas, pese a encontrarse en etapa de contracción.

Según Sergio Grez, la participación femenina en el POS y las instancias asociadas a éste, como el Centro Belén de Sárraga, en general fue baja y constituyó una preocupación para su dirigencia, señalando que: "Una última explicación posible a este fenómeno se encontraría en el carácter de los mensajes de la prensa socialista, que engloba en un todo las demandas de la mujer junto a los de los hombres, sin desarrollar un discurso sobre la opresión masculina, como sí lo hacía, en contraste, la prensa anarquista" ${ }^{50}$.

En medio del desgaste, Belén de Sárraga visitó nuevamente el norte de Chile en 1915, sus conferencias fueron altamente concurridas y no estuvieron exentas de disturbios y enfrentamientos:

"La primera conferencia dada antenoche por la infatigable propagandista anti-clerical Belén de Sárraga, puso en alarma a los elementos clericales, que como una horda de salvajes

\footnotetext{
${ }^{48}$ Hutchison, Elizabeth. 2006. Labores propias de su sexo, p. 79.

${ }^{49}$ Boletín de la Oficina del Trabajo, N9, II semestre de 1914, pp. 17-18.

${ }^{50} \mathrm{Grez}$, Sergio. 2011. Historia del comunismo en Chile. La era de Recabarren (1912-1924), Santiago, Lom Ediciones, p. 75.
} 
invadieron el local, y prorrumpieron en desaforados gritos de protesta en cuanto la valiente luchadora apareció en escena lanzando al proscenio toda clase de inmundicias. [...] Las manifestaciones callejeras se sucedieron unas a otras, produciéndose varios choques entre los dos bandos" ${ }^{\prime 51}$.

Esta segunda visita infundió nuevos aires al Centro, sin embargo no logró fortalecer su orgánica y, en lo sucesivo, sus actividades no equiparon la masividad del primer año de funcionamiento. Aunque continuó operando hasta 1918, su importancia relativa entre el movimiento obrero había disminuido notoriamente.

El Centro Belén de Sárraga de lquique, cuestionó las estructuras socioculturales que definían la subordinación de la mujer y se posicionaban políticamente desde la acción emancipadora. La orientación teórica y social de esta orgánica apuntaba hacia la difusión de las ideas librepensadoras y anticlericales como una estrategia para abolir la dominación de las mujeres en tanto que eslabón fundamental en la cadena de dominación del hombre y la familia proletaria. El objetivo trazado en esa dirección correspondía también a la emancipación de la clase obrera en su conjunto. No obstante, esta emancipación no transgredía el ideal de la feminidad instalado socialmente, asociado a la mujer como madre y esposa, aunque sí criticó la sumisión y el confinamiento de las mujeres a las labores domésticas. En su conferencia sobre la mujer en la sociedad, Belén de Sárraga:

"Nos habló de la influencia de la mujer sobre el hombre y nos probó que aunque al hombre, las leyes civiles y eclesiásticas, le habían conferido autoridad sobre la mujer, ésta siempre por medio del ruego de la madre, el beso de la hija ó las lágrimas de la esposa, conseguirá vencer sobre los sentimientos del hombre [...] y concluído ó muerto el fanatismo de los rezos y letanías, la mujer endulsará la vida dando espansión á sus mas nobles sentimientos amorosos, su palabra vivificante hará que el hombre, aun cuando el peso de los años corone de nieve su cabeza, ella, la mujer, sabrá darle nuevos bríos y enerjías para continuar la vida feliz en medio de la dulce paz inalterable del hogar, producida y mantenida constantemente por la mujer intelijente y amorosa." 52

Por tanto, estas ideas emancipatorias apuntan a la construcción de una sociedad futura basada en la libertad, justicia y la igualdad entre hombres y mujeres, reconociendo en plenitud sus derechos, sin embargo esta proyección se basa en representaciones del género propias del contexto, las cuales no son cuestionadas como el origen de la opresión de las mujeres. De esta forma, la mantención de estos roles no aparece como contradictoria con la construcción de la sociedad socialista, puesto que el origen de la opresión de las mujeres estaría fuera de dichas

\footnotetext{
51 “La primera conferencia de Belén de Sárraga”, EDT, 19 de mayo de 1915.

52 "Nuevo éxito de la señora Belén de Sárraga en el tema La mujer como entidad social", EDT, 13 de marzo de 1913.
} 
categorías: en el seno del fanatismo religioso y del capitalismo. En el discurso pronunciado por Rosario de Barnes en el marco de la conmemoración del 1 de mayo de 1913, se esbozan precisamente ideas que refuerzan los roles de madre y esposa:

"Luchad, con aquellas rancias é incalificables ideas que encierran algunos inconscientes aun 'La mujer en su cocina á quehaceres domésticos, si es pobre, si es rica en sus insignificantes quehaceres ó innumerables pasatiempos'. No señoras fuera esas máximas de retroceso, ignorancia, esclavitud moral é intelectual. Abrazad la instrucción, reconquistemos nuestros derechos usurpados y ayudemos, colaboremos conjuntamente con nuestros esposos ó hermanos en la obra de redención. [A las jóvenes] Comprended que pronto seréis futuras esposas y madres de familias y vuestro sagrado é ineludible deber será como mujeres conscientes, educar y formar el corazón y el cerebro de vuestros tiernos hijos..." ${ }^{13}$

La emancipación de las mujeres, por tanto, implicaba su acercamiento a las verdades científicas, acabar con la influencia clerical y promover el librepensamiento para mejorar su posición social, lo cual no implicaba alterar las estructuras familiares ni los roles tradicionales. A partir de lo anterior, creemos importante desentramar la noción de feminismo que las propias mujeres del periodo (desde el mundo popular y cercanas al socialismo) manejaban, cómo se definían o percibían en relación con ello.

Los Centros Belén de Sárraga y otras organizaciones librepensadoras se extendieron también en otros puntos del país, como el Centro Instructivo de Obreras Librepensadoras Luisa Michel de Antofagasta, y los centros El Despertar de la Mujer de Valparaíso y Viña del Mar ${ }^{54}$. A nuestro juicio, la innovación de esta forma orgánica radica en que surgen desde lógicas de participación de las propias mujeres y no como una versión femenina de las organizaciones de varones. Su contenido ideológico se basaba en posturas más radicales sobre de la condición de la mujer que las esbozadas hasta entonces, además, incorporaron como objetivo una transformación social profunda que contemplase su emancipación.

Estos centros han sido catalogados como la manifestación más elocuente del fenómeno del feminismo obrero en Chile, y si bien estamos de acuerdo con esta visión general, consideramos que es necesario entenderlos en un sentido de continuidad histórica y como parte de un amplio proceso sostenido en el tiempo, correspondiente a la configuración de una identidad en torno al género y la clase que definió la politización de las mujeres mediante las múltiples experiencias asociativas del periodo y que hemos analizado en este artículo.

\footnotetext{
53 "Ecos del $1^{\circ}$ de Mayo", EDT, 6 de mayo de 1913.

${ }^{54}$ Lagos, Manuel. 2017. El anarquismo y la emancipación de la mujer en Chile (1890-1927), Santiago, Editorial Quimantú, pp. 188-189.
} 
Entre 1917 y 1918, se puede percibir un decaimiento no sólo del Centro Belén de Sárraga de lquique, sino que de forma general de las organizaciones autónomas de mujeres en el movimiento obrero. Pese a esta tendencia, la participación sociopolítica de mujeres no se detuvo, sino más bien se reorientó hacia los partidos y federaciones obreras mixtas, según indica Ana María Carrasco:

"Llegamos luego a la década de los años 1920 donde aparecen una serie de organizaciones e instancias que llaman a agruparse y participar de manera activa a las mujeres obreras de las ciudades y oficinas salitreras de la pampa nortina. La totalidad de las organizaciones de este tipo que surgen se adhieren sea a la IWW o a la FOCH, formando parte de Consejos, Secciones o Federaciones Femeninas" ${ }^{\prime 5}$.

El fin del Ciclo de Expansión del Salitre es también, en nuestra opinión, el principio de la disolución de la sociedad que se desarrolló en Iquique entre 1872 y 1918. El desarrollo de esta compleja sociedad regional multiétnica se vio interrumpido por la chilenización compulsiva de la provincia que significó "la ruptura de la confianza comunitaria, el fin de un tejido social plurinacional, para imponer una nacionalidad dominante" ${ }^{26}$. La parcial disolución de la sociedad regional salitrera por la violencia xenofóbica es visible en diversos documentos de la administración pública de la época y coincide con los años finales del predominio del salitre en el mercado internacional. Los grandes problemas sociales, cuya presión parecía estallar hacia fines de la década, se atenuaron no por la intervención de un nuevo tipo de Estado, si no que por la descompresión que significó el éxodo laboral determinado por la crisis salitrera. La sociedad regional remanente y la ciudad de lquique entraron en una nueva época caracterizada por la depresión económica, el despoblamiento y nuevas dinámicas de organización social y política.

\section{Conclusiones}

El género, en tanto que elemento articulador de las relaciones sociales de poder, influyó en las formas de participación sociopolítica de las mujeres en el movimiento obrero iquiqueño. Las distintas formas de organización analizadas en este periodo se inscriben en un fenómeno más amplio, de búsqueda de sentidos y resignificación de la participación política por parte de las mujeres, como actrices históricas que reclaman su espacio en la esfera pública, constituyéndose en sujetos políticos. Tanto las sociedades mutuales, el gremio de profesoras, la articulación de las comerciantes ambulantes y las librepensadoras del Centro Belén de Sárraga, nos remiten al dinamismo de inicios del siglo XX que operó en el sentido de ampliar el sentido de lo político.

\footnotetext{
55 Carrasco, Ana. 2018. Hacia un nuevo significado de la política. p. 248.

56 González, Sergio. 2007. El dios cautivo: las ligas patrióticas en la chilenización compulsiva de Tarapacá (19101922), Santiago, LOM Ediciones, p.83.
} 
A diferencia de lo ocurrido con las organizaciones obreras masculinas, la articulación de las mujeres de sectores populares no se avocó prioritariamente a la acción de tipo sindical, aunque sí abogaron por posiciones clasistas, en alianza con el Partido Obrero Socialista. El foco puesto en el oscurantismo religioso, permitió al Centro Belén de Sárraga indagar de forma pionera en los orígenes de la condición de la mujer, identificada con la influencia de la Iglesia y la explotación del capitalismo.

Consideramos necesario entender la visita de Belén de Sárraga y la fundación del Centro Anticlerical de Iquique en términos de continuidad histórica y no como coyuntura inicial del movimiento de mujeres y feministas, tanto en lquique como en Chile, por diversos motivos. En primer lugar, la politización de las mujeres fue un proceso vinculado a las transformaciones operadas a nivel social, económico y político en el periodo estudiado, por ello es necesario situar el hito de la visita de Sárraga en la complejidad de su contexto para comprender su relevancia, alcances y efectos. En segundo lugar, hay que considerar que el movimiento de mujeres y feministas hacia inicios del siglo XX contemplaba diferentes clases sociales, demandas y formas de participación, las que van desde las élites católicas agrupadas en torno a la caridad, pasando por las intelectuales liberales y sectores medios y, por supuesto, por las mujeres de sectores populares, por ende, no es posible asignar a un solo hito la característica de ser el inicio de un movimiento tan diverso. En ese sentido, proponemos pensar la formación del movimiento de mujeres como un proceso histórico de mayor complejidad y de larga duración, marcado por una práctica extendida durante décadas previas a la visita de Sárraga entre las mujeres, de generar instancias de acción política que tensionaban los límites de la participación restringida únicamente a los hombres.

Finalmente, consideramos que la definición de "política" que estrecha los límites de la acción a lo partidario y la negociación con esferas institucionales no puede aplicarse al conjunto de la sociabilidad del movimiento obrero que, efectivamente, fueron altamente politizados. De este modo, proponemos evaluar el significado de lo político para cuenta de los diálogos que se establecen entre el sujeto, de forma individual y colectiva, y los múltiples centros de podersociales, religiosos, culturales, económicos o simbólicos. En ese sentido, las organizaciones de mujeres comenzaron un diálogo tanto con la autoridad política formal como con aquellas que sustentan los constructos culturales de género y el poder patriarcal. Por tanto, en la identidad de la clase obrera chilena, a partir del caso de las mujeres de lquique, se visualiza el factor de género como un elemento ordenador de las relaciones sociales que, a su vez, experimenta un constante cambio puesto que tiene historicidad, de modo que el análisis de la sociabilidad popular debe considerar la dimensión de género para alcanzar una mayor y más democrática interpretación de la formación de la clase obrera en Chile. 


\section{Referencias citadas}

\section{Fuentes documentales}

Archivo Histórico del Museo Regional de Iquique, Fondo Ilustre Municipalidad de Iquique, Alcaldía Municipal.

Archivo Nacional de la Administración, Fondo Dirección del Trabajo.

\section{Bibliografía}

Antivilo, Julia. 2019. “Crónica de un torbellino libertario en América Latina. Belén de Sárraga (19061950)", en Revista Historia de las Mujeres, no 191. Disponible en: http://www.cemhal.org/anteriores/2019_2020/24Antivilo.pdf. (Consultado el 10 de octubre de 2020).

Artaza, Pablo. 2006. "La Mancomunal de Obreros de Iquique: su propuesta de vinculación entre movimiento social y politización popular. 1900-1909", en Revista Espacio Regional, Vol. 1, №3, Osorno, pp. 9-18.

Brito, Alejandra. 2005. De mujer independiente a madre, de peón a padre proveedor. La Construcción de Identidades de Género en la Sociedad Popular Chilena 1880-1930, Concepción, Ediciones Escaparate.

Carrasco, Ana María. 2014. "Remolinos de la Pampa. Industria Salitrera y Movimientos de Mujeres (19101930)", en Estudios Atacameños, N48, San Pedro de Atacama, pp. 157-174.

Carrasco, Ana María. 2018. Hacia un nuevo significado de la política. Los movimientos de mujeres en el extremo norte de Chile (1910-1973), Arica, Ediciones de la Universidad de Tarapacá.

Gálvez, A. (ed.) 2021. Históricas. Movimientos feministas y de mujeres en Chile (1850-2020), Santiago, Lom Ediciones, p. 22.

Gaviola, Edda (et.al.). 1986. Queremos votar en las próximas elecciones. Historia del movimiento femenino chileno: 1913-1952, Santiago, Ediciones La Morada.

Grez, Sergio. 2007. “1890-1907: De una huelga general a otra. Continuidades y rupturas del movimiento popular en Chile", en Revista Cyber Humanitatis № 41. Disponible en: https://web.uchile.cl/vignette/cyberhumanitatis/CDA/texto_simple2/0,1255,SCID\%253D21033\%25 26ISID\%253D730,00.html. (Consultado el 10 de julio de 2018).

Grez, Sergio. 2011. Historia del comunismo en Chile. La era de Recabarren (1912-1924), Santiago, Lom Ediciones.

González, Sergio. 2007. El dios cautivo: las ligas patrióticas en la chilenización compulsiva de Tarapacá (1910-1922), Santiago, Lom Ediciones.

González, Sergio. 2016. "Las inflexiones de inicio y término del ciclo de expansión del salitre (1872-1919). Una crítica al nacionalismo metodológico" en González, Sergio, Matamunqui. El ciclo de expansión del nitrato de Chile. La sociedad pampina y su industria, Santiago, RIL Editores, pp. 209-232.

Hutchison, Elizabeth. 2006. Labores propias de su sexo. Género, políticas y trabajo en Chile urbano 19001930, Santiago, Lom Ediciones.

Illanes, María Angélica. 2003. Chile des-centrado. Formación socio-cultural republicana y transición capitalista (1810-1910), Santiago, Lom Ediciones. 
Lagos, Manuel. 2017. El anarquismo y la emancipación de la mujer en Chile (1890-1927), Santiago, Editorial Quimantú.

Montero, Claudia. 2018. Y también hicieron periódicos. Cien años de prensa de mujeres en Chile 18501950, Santiago, Editorial Hueders.

Núñez, Isabel. 2008. "El sujeto femenino en la pampa salitrera. Una mirada desde los estudios de género", en Diálogo Andino. Revista de Historia, Geografía y Cultura Andina no31, Arica, pp. 91-100. Disponible en: http://dialogoandino.cl/wp-content/uploads/2016/07/06-NUNU0303EZ-DA-31.pdf. (Consultado el 10 de mayo de 2021).

Oteiza, Rodrigo. 2019. Mujeres obreras. Organización y sociabilidad en la sociedad de Socorros Mutuos Unión y Fraternidad de Obreras de Valparaíso 1892-1897, Pontificia Universidad Católica de Valparaíso, Tesis para optar al grado de Magíster en Historia.

Pinto, Julio. 2002. "De proyectos y desarraigos: la sociedad latinoamericana frente a la experiencia de la modernidad", Revista Contribuciones científicas y tecnológicas, № 130, Santiago, pp. 95-113.

Pinto, Julio. 2004. "Discurso de clase en el ciclo salitrero: la construcción ideológica del sujeto obrero en Chile, 1890-1912", en Revista de Historia Social y de las Mentalidades, Vol. 12, № 2, Santiago, pp. 131-198.

Romero, Luis Alberto. 1990. "Los sectores populares urbanos como sujetos históricos", Proposiciones N¹9, Santiago, Ediciones SUR, pp.268-278.

Salazar, Gabriel y Pinto, Julio. 1999. Historia contemporánea de Chile Tomo I. Estado, legitimidad y ciudadanía, Santiago, Lom Ediciones.

Scott, Joan W. 1996. “El género: una categoría útil para el análisis histórico”, en Lamas, Marta, El género. La construcción cultural de la diferencia sexual, Ciudad de México, UNAM, pp. 265-302.

Venegas, Fernando. 2003. Víctor Domingo Silva Endeiza: una vida sin detenciones (1882-1960), Limache, Consejo Nacional del Libro y la Lectura.

Vitale, Luis y Antivilo, Julia. 1999. Belén de Sárraga: precursora del feminismo hispanoamericano, Santiago, Editorial CESOC. 